\title{
Diagnosing and Managing Patients with Reactions to Radiocontrast Media
}

\section{Knut Brockow, MD $\odot$}

\author{
Address \\ Department of Dermatology and Allergy Biederstein, School of Medicine, Techni- \\ cal University of Munich, Biedersteiner Strasse 29, 80802, Munich, Germany \\ Email: knut.brockow@tum.de
}

Published online: 23 August 2021

(C) The Author(s) 2021

This article is part of the Topical Collection on Drug Allergy

Keywords Radio contrast media - Hypersensitivity - Anaphylaxis - Exanthem - Diagnosis - Allergy · Skin test Provocation test . Premedication

\begin{abstract}
Purpose of the review Iodinated radio contrast media (RCM) belong to the most common elicitors of drug hypersensitivity reactions (HR). Urticaria or anaphylaxis may occur $\leq 1(-6)$ hour(s) (immediate HR) and exanthems (non-immediate HR) develop $>6 \mathrm{~h}$ after application of RCM. Evidence for an immunologic mechanism of RCM HR against the different RCM benzene ring molecules and the benefit of allergological testing in patients with previous hypersensitivity reactions is progressively increasing.

Recent findings Positive skin tests can confirm allergy in patients with previous reactions to RCM and help to select alternative better tolerated RCMs. Severe hypersensitivity reactions are mainly caused by an allergic mechanism, whereas the majority of nonsevere reactions appear to be non-allergic. Skin testing is highly recommended to help identify allergic hypersensitivity reactions and to select alternatives. Using structurally different RCM is more effective than premedication for the prevention of future reactions. Drug provocation tests to RCM have been increasingly used, but are not yet standardized among different centers.

Summary In patients with previous severe hypersensitivity reactions to RCM, skin testing is recommended. For future RCM-enhanced examinations in patients with previous reactions, structurally different, skin test-negative preparations should be applied. Drug provocation tests do confirm or exclude RCM hypersensitivity or may demonstrate tolerability of alternative RCMs.
\end{abstract}




\section{Introduction}

Modern medicine increasingly relies on examinations with radio contrast media (RCM) for diagnostic purposes, whereas these are normally well tolerated. However, because of more than 70 million applications of RCM administered worldwide per year, adverse reactions are not uncommon after their use [1]. A part of the reported reactions are predictable toxic reactions, such as nephrotoxicity, neurotoxicity, vasovagal reactions, transient warmth/flushing, metallic taste, pallor, weakness, nausea, and vomiting as well as bradycardia. Another part is even causally unrelated to exposure to RCM, e.g., stressinduced (spontaneous) acute urticaria, exanthems elicited by other drugs given at the same time, or unspecific subjective symptoms often associated with anxiety. However, thirdly, allergic and non-allergic hypersensitivity reactions do occur and present either only with cutaneous reactions (urticaria, pruritus, angioedema, exanthem) or with systemic manifestations including anaphylaxis [2•]. This article focusses on recent advances in our understanding of hypersensitivity reactions to RCM.

\section{Chronological classification of radiocontrast media reactions}

RCM hypersensitivity reactions may occur either immediately within 1 (in very exceptional cases history of up to six) hour(s) after RCM administration (immediate hypersensitivity reactions, IHR) or non-immediate hypersensitivity reactions (NIHR) developing $>6 \mathrm{~h}$, mostly $1-3$ days and up to 10 days after RCM application $[3,4]$. Almost all IHR start within $1 \mathrm{~h}$, most severe reactions (96\%) within 20 min and the majority of IHRs to RCM occur even within the first 5 min after RCM administration [5]. In IHRs, symptoms resemble manifestations also seen in anaphylaxis ranging from isolated skin involvement to full anaphylaxis involving more than one organ system and in NIHRs present with exanthems, mostly maculopapular exanthems [6].

\section{Risk factors for radiocontrast media reactions}

Reported incidences of hypersensitivity reactions to RCM vary widely because of different definitions of anaphylaxis, IHR, NIHR, and RCM attributed to toxicity, use of premedication. Mild IHR to nowadays non-ionic (low osmolar) RCM are estimated to occur in $0.5-2.0 \%$ administrations and severe reactions in $0.02-$ $0.04 \%$ [5]. The incidence of NIHR to RCM remains unclear, but skin reactions may be around 0.5 to $3 \%$; with possibly a higher incidence for the dimeric isoosmolar RCM iodixanol $[7,8]$. Whereas several other minor factors have been discussed in individual studies, the only well-proven major risk factor for IHR as well as for NIHR is re-exposure after previous reaction to RCM. Interestingly, a previous IHR is no risk factor for an NIHR and vice versa. IHRs to RCM are substantially less often reported for intra-arterial and for extravascular (e.g., gastrointestinal, genitourinary) administrations $[9,10]$.

\section{Clinical manifestations}

Manifestations of IHR to RCM range from mild skin symptoms, such as urticaria, to anaphylaxis $[11,12 \bullet$, 13•]. Fatal anaphylaxis does occur with an estimated fatality rate of approximately 1 to 2 per 100,000 procedures [14-16]. 
Most IHR present with cutaneous symptoms, such as urticaria/angioedema and pruritus [11]. Anaphylaxis affects mostly the skin together with an involvement of other organ systems, e.g., bronchospasm and wheezing, additional nausea and vomiting, or tachycardia and hypotension resulting in anaphylactic shock. An acute coronary syndrome caused by reduced blood flow to the heart may develop [17]. Maculopapular exanthem (MPE) of mild or moderate severity is by far the most common manifestation of NIHR [13•]. Other exanthems, such as severe cutaneous adverse reactions (e.g., drug reaction with eosinophilia and systemic symptoms (DRESS), Stevens-Johnson syndrome (SIS), toxic epidermal necrolysis (TEN) or acute generalized exanthematous pustulosis (AGEP)), are rather uncommon $[18,19]$. Also, erythema exsudativum multiforme, bullous fixed drug eruption, and pompholyx are exceptional and have been reported only in individual cases [19].

\section{Mechanisms of RCM hypersensitivity}

Until several years ago, the mechanism has been considered non-allergic. During the last years, we began to believe that RCM reactions may have an immunological basis and be allergic [20]. Evidence to support the hypothesis that patients with severe anaphylaxis primarily have an immunoglobulin E (IgE)-mediated allergic mechanism for IHR to RCM is accumulating $[21 \bullet \bullet]$. In support, a prospective study reported allergy as demonstrated by positive skin test in one in tenth, a quarter, half, and all patients with cutaneous, moderate-systemic, life-threatening anaphylaxis, and cardiac arrest, respectively [2•]. Further evidence for such an IgE- or mast cell-mediated mechanism includes positive skin tests, tryptase and histamine release during the reaction, and basophil activation tests [20]. However, still in the majority of patients with IHR of mild to moderate severity, no sensitization can be demonstrated; in those skin or basophil activation tests to RCM, possible indirect means of demonstrating allergy remain negative and a non-allergic mechanism is still assumed. A mechanism for non-allergic RCM reactions, which is demonstrable selectively in reacting patients, but not in tolerant controls, yet has been demonstrated [20]. In a mouse model, the RCM iopamidol activated the mast cell-specific receptor MRGPR X2 [22•].

The mechanism of NIHRs to RCM is T-cell mediated evidenced by a typical time of onset of delayed allergic reactions, by the clinical picture and the duration of the exanthem closely resembling other drug exanthems, as well as by positive patch and delayed readings of intradermal tests, ex vivo activated T-cells in positive skin test sites and by positive lymphocyte transformation tests (LTT) [4]. An underlying type IV Tcellular allergic mechanism often can be demonstrated by positive delayed skin tests, particularly in clearly defined and early tested patients, but is not always present $[4,23,24 \bullet \bullet]$. The responsible allergic structure within the RCM molecule is its benzene ring in the majority of patients and not the iodine ion. Positive skin tests to iodine or positive provocation tests with Lugol's solution have only been reported rarely in nonimmediate reactions $[24 \bullet \bullet, 25]$. However, in individual patients with maculopapulous exanthem, iodine hypersensitivity may be present and 
these may be identified by open repeated application test of iodine solution even without provocation $[24 \bullet \bullet]$.

\section{Diagnostic workup of patients with RCM hypersensitivity}

\section{Indication for testing}

Not all patients with reported adverse reactions after receiving RCM profit from

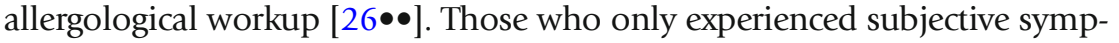
toms, particularly if only one symptom, e.g., feeling of warmth or erythema on injection side, nausea, paresthesia, headache, or dizziness or onset of other nonspecific symptoms between 1 and $6 \mathrm{~h}$ after the administration, most likely did suffer from a non-severe toxic reaction or causally unrelated reaction and will not show positive skin tests. Prescreening unselected patients by skin testing does not predict future hypersensitivity reactions [27•]. On the other hand, in patients reporting urticaria/angioedema/bronchospasm or suspicion of anaphylaxis occurring immediately and patients with exanthems presenting after $6 \mathrm{~h}$ to 7 days consistent with NIHR, there is an indication for allergy workup

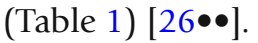

\section{Skin testing of patients}

The best time point for skin testing patients with RCM hypersensitivity is unknown. However, as skin tests 2-6 month after IHR and NIHR have shown best sensitivity in one multicenter study, this time interval is recommended also for allergy testing, although positive skin tests several years after the incident have been described in individual patients [11]. Although in Europe, skin testing has been reported to be helpful for diagnosing RCM hypersensitivity, this has only recently increasingly been consented by experts also in the USA $[28 \bullet, 29]$. It has been hypothesized that skin testing differentiates allergy from non-allergic reactions, and thus identifies a safe skin test-negative alternative, which has been confirmed by intravenous provocation $[24 \bullet \bullet, 30]$.

The skin test procedure depends on the suspected mechanism [31 $\bullet$. For IHR, skin prick tests (SPT) and intradermal tests (IDT) with immediate readings are done. For NIHR, patch test and late readings for SPT and IDT are crucial and will be added. In NIHR, IDT are more sensitive than patch tests. Skin tests are

Table 1. Indications for allergy workup after reported adverse reactions to RCM

Generalized cutaneous reaction: urticaria, angioedema, flushing

Isolated bronchospasm

Anaphylaxis

Delayed-appearing urticaria and angioedema (causal relationship questionable)

Maculopapular exanthema

Morphological variants of exanthema (e.g., fixed drug eruption, SDRIFE, AGEP)

Severe bullous skin reactions (SJS, TEN), severe systemic reaction (DRESS) (only skin tests, generally no drug provocation test, individual decisions possible)

SJS Stevens-Johnson syndrome; TEN toxic epidermal necrolysis; FDE fixed drug eruption; DRESS drug reaction with eosinophilia and systemic symptoms; SDRIFE symmetric drug-related intertriginous and flexural exanthema; AGEP acute generalized exanthematous pustulosis 
performed with the culprit contrast agent and with a panel of alternative contrast agents (consider agents available in the institution performing future contrast imaging for the patient), if possible, for selecting a skin test-negative RCM for subsequent procedures $[26 \bullet \bullet, 31 \bullet]$. For IHR, RCM are recommended to be used undiluted at $300-320 \mathrm{mg} / \mathrm{ml}$ on the forearm or upper back for SPT as well as diluted at 1:10 for IDT. Testing should start by performing SPT and, if negative, be continued with IDT. In NIHR, IDT is done with 1:10 dilution of the standard concentration of RCM and delayed reading, e.g., after 48 and $72 \mathrm{~h}$. Testing with undiluted RCM can be considered for higher sensitivity; however, immediate positive reactions could be irritative. In addition, a patch test on the upper back with undiluted standard solution of RCM with readings at $48 \mathrm{~h}$ and a further delayed reading (72-120 h) is recommended for optimal sensitivity. Although the sensitivity of late readings of IDT is by far higher than that of patch tests, in individual patients, patch tests exceptionally may be positive to a RCM with negative IDT. Thus, several centers prefer to test all their patients with IDT and patch tests in parallel. Validity of different reading times for skin tests has not yet been formally compared and patients should additionally be instructed to return for additional readings in case of any later appearing skin reaction at the test site [26••]. Although the IDT is more sensitive as compared to the patch test, using both tests may enhance sensitivity.

Sensitivity of skin tests appears to be higher, if the time interval between reaction and skin test is 2-6 months [11]. Also a higher rate of positive skin tests can be seen in more severe reactions $[2 \bullet, 11]$. In a meta-analysis, $52 \%$ of skin tests were positive in severe IHRs to RCM, whereas the rate dropped to $17 \%$, if mild and

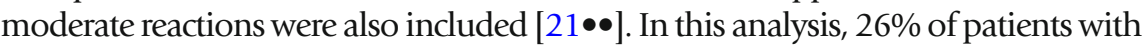
NIHR had positive skin tests. In the personal experience of the author, the rate is considerably higher, if patients with NIHR have been diagnosed in our department and tested within a few weeks afterwards. The specificity of skin tests is high: 95\% for undiluted SPT, $91-96 \%$ for 1/10 diluted IDT in IHR and is considered to be close to $100 \%$ for all skin tests in NIHR [11, 21••]. Cross-sensitivity between RCM in skin testing and lymphocyte transformation test does occur and is higher in NIHR as compared to IHR $[11,32 \bullet]$. The pattern of cross-reactivity of different RCMs has been analyzed and cross-reactivity of iobitridol to other RCM has been reported to be low in NIHR [32•,33,34•], which may be related to its R1 chain being different from that of other RCMs [35]. For IHR, the isoosmolar RCM iodixanol appears to have a low rate of IHRs, and among low osmolar RCM, some agents (e.g., iomeprol) have recently been associated with higher reaction rates than others (e.g., iohexol) [36, 37].

During the immediate anaphylactic reaction, measuring increased tryptase levels in serum 1 to $4 \mathrm{~h}$ after the onset of the reaction can confirm the diagnosis of anaphylaxis, if levels increase sufficiently in comparison to baseline serum tryptase levels [38]. Measurements of increased histamine levels a few minutes after reaction onset is less practicable because of difficulties in probe handling, and lower availability of the commercial assay. The basophil activation test (BAT) has been reported to confirm the diagnosis of IHR to RCM in few studies [39-41]. Specificity was high and has been estimated $88.4-100 \%$, whereas sensitivity was moderate (46-62\%) [39, 40]. In NIHR, lymphocyte 
transformation tests (LTT) may be positive and RCM-reactive T cell-lines and clones have been isolated for experimental purposes, but appear to have a lower sensitivity as compared to skin tests [42].

\title{
Drug provocation test (DPT)
}

DPT with RCM has come up in the recent years and generally has been shown to be safe in the hands of experienced centers, although available protocols still are diverse and require standardization. Intravenous DPT can be either done with the skin test-negative culprit to exclude RCM allergy in a questionable causality or with an alternative skin test-negative RCM to find a substitute to be checked for toler-

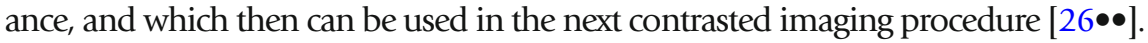
For DPT, adequate safety precautions should be taken and it should be done in an experienced setting. Still different protocols are used for DPT without consensus $[24 \bullet \bullet, 32 \bullet, 33,39,43 \bullet, 44]$. On the other hand, studies have shown that reexposure of an alternative skin test-negative RCM is quite safe, if a RCM examination is needed. That brings up the question, when DPT in contrast to re-exposition is required. Performing DPT may be particularly considered in patients with severe anaphylaxis using a skin test-negative alternative substance. It is contraindicated in a patient with renal insufficiency, hyperthyroidism, radioactive iodine therapy, pregnant, and breast-feeding women [26••]. RCM-induced nephropathy has to be avoided [45]. The decision needs to be taken based on a risk-benefit analysis of each patient.

\section{Management of patients with RCM hypersensitivity}

\author{
In urgent need of RCM
}

Different principal options dependent on the principal need for and urgency for RCM imaging are available for patients with previous RCM hypersensitivity reactions from total avoidance to drug provocation test with skin test-negative RCM (Table 2). If patients with a history of RCM hypersensitivity have an immediate and urgent need of another RCM-based imaging and no suitable imaging alternative (e.g., magnet resonance tomography, native CT- or MR-scan) is available, in patients with mild IHR (urticaria \pm angioedema) or mild NIHR (maculopapular exanthem), imaging with a non-culprit RCM can be considered under emergency preparedness and after premedication, because of the low risk of an allergic reaction and because premedication suppresses the majority of non-allergic reactions, which generally are of mild or moderate severity (Fig. 1) [26••, 31]. As it has been reported that changing the RCM from the culprit to a different RCM in a patient with previous RCM reaction may be more effective than premedication with single dose antihistamine or with single dose corticosteroid, changing the RCM is recommended in all patients [46, 47]. Different premedication protocols have been published for IHR, and a protocol using a combination of H1antihistamine (e.g., $50 \mathrm{mg}$ diphenhydramine $1 \mathrm{~h}$ before application) and corticosteroids (e.g., $50 \mathrm{mg}$ prednisone 13, 7, and $1 \mathrm{~h}$ before application) is often cited and may be considered) [28•]. The efficiency of premedication is likely to be low, mostly effective in suppressing non-allergic non-severe reactions and may be given considering risk (adverse effects)/benefit (possible small reduction of reaction frequency and severity, particularly mild reactions) ratio for patients. In diabetic patients, postprocedure surrogate markers of adverse events (blood pressure, 
Table 2. Management options in patients with prior hypersensitivity reaction (HR) to iodinated radiocontrast media (RCM) (adapted from [26・•])

\begin{tabular}{|c|c|c|c|}
\hline Management & Advantages & Disadvantages & Patient selection \\
\hline Avoidance & Safety & $\begin{array}{l}\text { RCM examination may } \\
\text { be urgently needed } \\
\text { Diagnosis unresolved }\end{array}$ & $\begin{array}{l}\text { Patients with other diagnostic options } \\
\text { (e.g., magnet resonance } \\
\text { tomography) } \\
\text { Patients without urgent need for RCM }\end{array}$ \\
\hline Premedication & $\begin{array}{l}\text { Well-established } \\
\text { Reduces reaction rate } \\
\text { particularly of non-severe } \\
\text { reactions }\end{array}$ & $\begin{array}{l}\text { Probably not helpful to } \\
\text { prevent severe } \\
\text { allergic HR } \\
\text { Breakthrough reactions } \\
\text { False sense of security } \\
\text { Different regimes } \\
\text { Risk of adverse effects to } \\
\text { premedication }\end{array}$ & $\begin{array}{l}\text { Patients with non-allergic reactions } \\
\text { without positive skin test } \\
\text { Patients where skin tests cannot be } \\
\text { performed } \\
\text { Patients with very severe reactions as an } \\
\text { additional safety measure }\end{array}$ \\
\hline $\begin{array}{l}\text { Use of a non-culprit } \\
\text { alternative by } \\
\text { history }\end{array}$ & $\begin{array}{l}\text { Easy } \\
\text { Reduction of reaction rates } \\
\text { demonstrated }\end{array}$ & $\begin{array}{l}\text { Weak evidence } \\
\text { Cross-reactivity not well } \\
\text { studied }\end{array}$ & $\begin{array}{l}\text { Patients with immediate urgent need of } \\
\text { RCM without possibility of skin tests } \\
\text { Patients with non-severe probable toxic } \\
\text { reactions }\end{array}$ \\
\hline $\begin{array}{l}\text { Use of ST-negative } \\
\text { alternative RCM }\end{array}$ & $\begin{array}{l}\text { Good negative predictive value } \\
\text { Omission of skin-test positive } \\
\text { RCM with high risk of } \\
\text { anaphylaxis }\end{array}$ & $\begin{array}{l}\text { Only few patients with } \\
\text { IHR have positive ST } \\
\text { No benefit for } \\
\text { non-allergic reactions } \\
\text { Expertise needed } \\
\text { Time consuming }\end{array}$ & $\begin{array}{l}\text { All patients with suspicion of IHR or } \\
\text { NIHR in whom skin tests can be } \\
\text { performed }\end{array}$ \\
\hline
\end{tabular}

glucose levels, medication use) were increased after RCM administration with premedication [48]. The setting should be as safe as possible, e.g., taking place in hospitals with code teams and with close observation (possibly using pulsoxymetry). Mastocytosis does not appear to be associated with a higher frequency of IHRs [49]. It has been reported that reducing injection speed and using lower dose are associated with a lower relative risk of an IHR to RCM [50•]. Also, extrinsic warming of the RCM was associated with a reduced IHR rate [51 $\bullet$. These measures may be applied to further reduce the reaction risk.

In patients with urgent need, but severe anaphylaxis, RCM should be best avoided and an allergological workup is necessary, if there is no imaging alternative. If RCM is considered indispensable, after a risk-benefit analysis, one may choose nevertheless to administer the non-culprit RCM, but only after premedication and with emergency preparedness including anesthesia standby. In this specific setting of immediate need, also desensitization may be considered, whereas in all other patients, proper allergy workup with skin tests and DPT is preferable and normally sufficient $[52,53]$. In patients with severe NIHR possibly beyond medical control, RCM avoidance and other alternative procedures have to be looked for even in case of urgent need. 


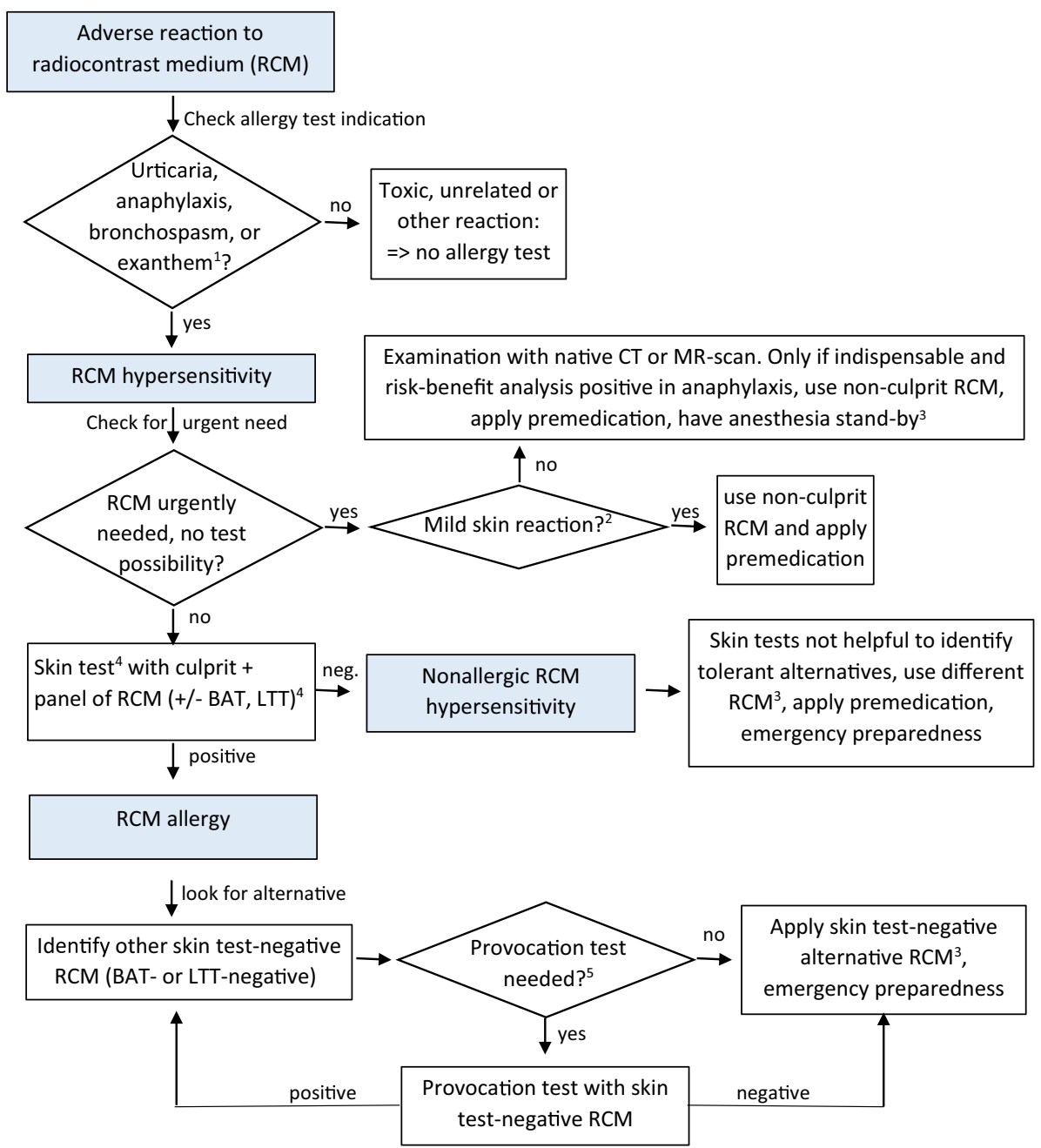

Fig. 1. Management of patients with previous radiocontrast medium reaction (adapted from [31•]). ${ }^{1}$ Including exanthem variants, however, after severe bullous exanthems or after reactions with systemic symptoms skin test can be done, but future total RCM avoidance is normally recommended; ${ }^{2}$ such as urticaria or "benign" maculopapular exanthema; ${ }^{3}$ not after severe bullous exanthems or after drug reaction with systemic symptoms: here RCM avoidance; ${ }^{4} \mathrm{BAT}=$ basophil activation test, and LTT= lymphocyte transformation test may be helpful in some cases; ${ }^{5}$ this is decided on a risk-benefit analysis, e.g. in patients with higher risk and more severe reactions in experienced allergy centers.

culprit RCM, a skin test-negative alternative can be administered without premedication under emergency preparedness and tolerance is expected. This strategy was successful in a number of studies $[24 \bullet \bullet, 30,54 \bullet]$, with only few others reporting different results [55]. Applying premedication can be considered in very severe IHRs, but its efficacy is unclear and adverse effects have to be considered. The culprit should be avoided as well as other skin test-positive RCMs. If available, BAT or LTT may supplement skin testing to select a RCM for future use, although cutoff values for positivity remain largely unvalidated. Whether DPT is advisable or direct re-exposition is preferable can be decided on an individual basis, e.g., depending on the severity of the reaction and 
availability of DPT. A negative DPT with a skin test-negative agent has a high negative predictive value of $>90 \%$ in the real life setting $[54 \bullet, 56]$. In patients with negative skin tests to the culprit and alternatives, a non-culprit RCM under emergency preparedness can be applied with premedication considered, as this appears to be particularly effective in the prevention of non-severe manifestations.

Contraindications for the further use of RCM may be those with very severe anaphylaxis after risk-benefit analysis and after severe bullous or systemic NIHR. However, these patients are very rare, and in the vast majority of patients, allergy testing in addition to changing the RCM substantially helps to increase safety of subsequent RCM exposures in patients with previous RCM hypersensitivity.

\section{Funding}

Open Access funding enabled and organized by Projekt DEAL.

\section{Declarations}

\section{Conflict of Interest}

Knut Brockow declares that he/she has no conflict of interest.

Open Access This article is licensed under a Creative Commons Attribution 4.0 International License, which permits use, sharing, adaptation, distribution and reproduction in any medium or format, as long as you give appropriate credit to the original author(s) and the source, provide a link to the Creative Commons licence, and indicate if changes were made. The images or other third party material in this article are included in the article's Creative Commons licence, unless indicated otherwise in a credit line to the material. If material is not included in the article's Creative Commons licence and your intended use is not permitted by statutory regulation or exceeds the permitted use, you will need to obtain permission directly from the copyright holder. To view a copy of this licence, visit http://creativecommons.org/licenses/by/4.0/.

\section{References and Recommended Reading}

Papers of particular interest, published recently, have been highlighted as:

- Of importance

-• Of major importance

1. Christiansen C. X-ray contrast media-an overview. Toxicology. 2005;209(2):185-7.

2.• Clement O, Dewachter P, Mouton-Faivre C, Nevoret C, Guilloux L, Bloch Morot E, et al. Immediate hypersensitivity to contrast agents: the French 5-year CIRTACI Study. EClinicalMedicine. 2018;1:51-6.

This study demonstrates that the probability of positive skin tests depends on the severity of anaphylaxis and on the skin test concentration used.

3. Schonmann C, Brockow K. Adverse reactions during procedures: hypersensitivity to contrast agents and 
dyes. Ann Allergy Asthma Immunol. 2020;124(2):156-64.

4. Brockow K, Christiansen C, Kanny G, Clement O, Barbaud A, Bircher A, et al. Management of hypersensitivity reactions to iodinated contrast media. Allergy. 2005;60(2):150-8.

5. Katayama H, Yamaguchi K, Kozuka T, Takashima T, Seez P, Matsuura K. Adverse reactions to ionic and nonionic contrast media. A report from the Japanese Committee on the Safety of Contrast Media. Radiology. 1990;175(3):621-8.

6. Brockow K, Ardern-Jones MR, Mockenhaupt M, Aberer W, Barbaud A, Caubet JC, et al. EAACI position paper on how to classify cutaneous manifestations of drug hypersensitivity. Allergy. 2019;74(1):14-27.

7. Webb JA, Stacul F, Thomsen HS, Morcos SK. Late adverse reactions to intravascular iodinated contrast media. Eur Radiol. 2003;13(1):181-4.

8. Sutton AG, Finn P, Grech ED, Hall JA, Stewart MJ, Davies A, et al. Early and late reactions after the use of iopamidol 340, ioxaglate 320, and iodixanol 320 in cardiac catheterization. Am Heart J. 2001;141(4):67783.

9. Endrikat J, Michel A, Kolbach R, Lengsfeld P, Vogtlander K. Risk of hypersensitivity reactions to iopromide after intra-arterial versus intravenous administration: a nested case-control analysis of 133,331 patients. Investig Radiol. 2020;55(1):38-44.

10. Kim YS, Choi YH, Cho YJ, Lee S, Yoon SH, Park CM, et al. Incidence of breakthrough reaction in patients with prior acute allergic-like reactions to iodinated contrast media according to the administration route. Korean J Radiol. 2018;19(2):352-7.

11. Brockow K, Romano A, Aberer W, Bircher AJ, Barbaud A, Bonadonna $\mathrm{P}$, et al. Skin testing in patients with hypersensitivity reactions to iodinated contrast media a European multicenter study. Allergy. 2009;64(2):234-41.

12. Tasker F, Fleming H, McNeill G, Creamer D, Walsh S. Contrast media and cutaneous reactions. Part 1. Immediate hypersensitivity reactions to contrast media and gadolinium deposition. Clin Exp Dermatol. 2019;44(8):839-4.

Useful overview on Immediate hypersensitivity reactions to contrast media and gadolinium deposition.

13. Tasker F, Fleming H, McNeill G, Creamer D, Walsh S. Contrast media and cutaneous reactions. Part 2: Delayed hypersensitivity reactions to iodinated contrast media. Clin Exp Dermatol. 2019;44(8):844-6.

Useful overview on non-immediate hypersensitivity reactions to contrast media and gadolinium deposition.

14. Brockow K, Vieluf D, Puschel K, Grosch J, Ring J. Increased postmortem serum mast cell tryptase in a fatal anaphylactoid reaction to nonionic radiocontrast medium. J Allergy Clin Immunol. 1999;104(1):237-8.

15. Sapra A, Bhandari P, Manek M, Gupta S, Sharma S. Fatal anaphylaxis to contrast a reality: a case report. Cureus. 2019;11(11):e6214.
16. Yang Z, Li R, Yue J, Wei Y, Zhang X, Yin R. Fatal contrast medium-induced adverse response to iohexol in carotid artery angioplasty: a case report. Medicine (Baltimore). 2019;98(33):e16758.

17. Shibuya K, Kasama S, Funada R, Katoh H, Tsushima Y. Kounis syndrome induced by contrast media: A case report and review of literature. Eur J Radiol Open. 2019;6:91-6.

18. Machet $\mathrm{P}$, Marce D, Ziyani Y, Dumont M, Cornillier $\mathrm{H}$, Jonville-Bera AP, et al. Acute generalized exanthematous pustulosis induced by iomeprol with crossreactivity to other iodinated contrast agents and mild reactions after rechallenge with iopromide and oral corticosteroid premedication. Contact Dermatitis. 2019;81(1):74-6.

19. Brockow K, Sanchez-Borges M. Hypersensitivity to contrast media and dyes. Immunol Allergy Clin N Am. 2014;34(3):547-64

20. Brockow K. Immediate and delayed reactions to radiocontrast media: is there an allergic mechanism? Immunol Allergy Clin N Am. 2009;29(3):453-68.

21.• Yoon SH, Lee SY, Kang HR, Kim JY, Hahn S, Park CM, et al. Skin tests in patients with hypersensitivity reaction to iodinated contrast media: a meta-analysis. Allergy. 2015;70(6):625-3.

Metaanalysis pooling study results on skin test positivity to RCM in the literature until 2015.

22. Jiang W, Hu S, Che D, An H, Liu R. A mast-cell-specific receptor mediates Iopamidol induced immediate IgEindependent anaphylactoid reactions. Int Immunopharmacol. 2019;75:10580.

Study associates mast cell release to the RCM Iopamidol to activation of the mast cell-specific receptor MRGPR X2 in a mouse model as a possible mechanism pf RCM hypersensitivity.

23. Brockow K, Becker EW, Worret WI, Ring J. Late skin test reactions to radiocontrast medium. J Allergy Clin Immunol. 1999;104(5):1107-8.

24.• Trautmann A, Brockow K, Behle V, Stoevesandt J. Radiocontrast media hypersensitivity: skin testing differentiates allergy from nonallergic reactions and identifies a safe alternative as proven by intravenous provocation. J Allergy Clin Immunol Pract. 2019;7(7):2218-2.

Study shows that skin tests can differentiate allergic from nonallergic RCM hypersensitivity with different severity and can identify safe alternative RCM which are tolerated.

25. Scherer K, Harr T, Bach S, Bircher AJ. The role of iodine in hypersensitivity reactions to radio contrast media. Clin Exp Allergy. 2010;40(3):468-75.

26.•• Torres MJ, Trautmann A, I. Böhm, Scherer K, Barbaud A, Bavbek S, et al. Practice parameters for diagnosing and managing iodinated contrast media hypersensitivity. Allergy. 2021;76(5):1325-1339. Recent uptodate position paper of the European Network on Drug Hypersensitivity on practical management of RCM hypersensitivity.

27. Lee JH, Kwon OY, Park SY, Seo B, Won HK, Kang Y, et al. Validation of the prescreening intradermal skin 
test for predicting hypersensitivity to iodinated contrast media: a prospective study with ICM challenge. J Allergy Clin Immunol Pract. 2020;8(1):267-72

28. Sánchez-Borges M, Aberer W, Brockow K, Celik GE, Cernadas J, Greenberger P, et al. Controversies in drug allergy: radiographic contrast media. J Allergy Clin Immunol Pract. 2019;7(1):61-65

The review summarizes controversies on RCM allergy diagnosis and management between Europe and USA.

29. Broyles AD, Banerji A, Barmettler S, Biggs CM, Blumenthal K, Brennan PJ, et al. Practical guidance for the evaluation and management of drug hypersensitivity: specific drugs. J Allergy Clin Immunol Pract. 2020;8(9S):S16-S116.

30. Kwon OY, Lee JH, Park SY, Seo B, Won HK, Kang Y, et al. Novel Strategy for the prevention of recurrent hypersensitivity reactions to radiocontrast media based on skin testing. J Allergy Clin Immunol Pract. 2019;7(8):2707-13.

31. Brockow K. Medical algorithm: diagnosis and treatment of radiocontrast media hypersensitivity. Allergy. 2020;75(5):1278-8.

One practical algorithm to manage RCM hypersensitivity.

32. Lerondeau B, Trechot P, Waton J, Poreaux C, Luc A, Schmutz JL, et al. Analysis of cross-reactivity among radiocontrast media in 97 hypersensitivity reactions. J Allergy Clin Immunol. 2016;137(2):633-.

Largest study analysing cross-reactivity in patients with RCM hypersensitivity defining different RCM classes, within which RCM are more probable to cross-react with each other.

33. Gracia-Bara MT, Moreno E, Laffond E, MunozBellido F, Lazaro M, Macias E, et al. Tolerability of iobitridol in patients with non-immediate hypersensitivity reactions to iodinated contrast media. Allergy. 2018.

34. Gaudin O, Deschamps O, Duong TA, Gener G, Paul M, Luciani A, et al. Cutaneous tests and interest of iobitridol in non-immediate hypersensitivity to contrast media: a case series of 43 patients. J Eur Acad Dermatol Venereol. 2020;34(4):e178-e8.

One very recent of several studies reporting iobitridol to be well tolerated in patients with non-immediate hypersensitivity reactions to other RCM because of a different chemical structure of the R1 side chain.

35. Borras J, El-Qutob D, Lopez R, Enrique E. Hypothesized epitope localization in hypersensitivity reactions to iodinated contrast media. J Investig Allergol Clin Immunol. 2019;29(1):82-3.

36. Lee SY, Kang DY, Kim JY, Yoon SH, Choi YH, Lee W, et al. Incidence and risk factors of immediate hypersensitivity reactions associated with low-osmolar iodinated contrast media: a longitudinal study based on a real-time monitoring system. J Investig Allergol Clin Immunol. 2019;29(6):444-50.

37. An J, Jung H, Kwon OY, Kang Y, Lee JH, Won HK, et al. Differences in adverse reactions among iodinated contrast media: analysis of the KAERS database. J Allergy Clin Immunol Pract. 2019;7(7):2205-11.
38. Valent $\mathrm{P}$, Bonadonna P, Hartmann K, Broesby-Olsen $\mathrm{S}$, Brockow K, Butterfield JH, et al. Why the $20 \%+2$ tryptase formula is a diagnostic gold standard for severe systemic mast cell activation and mast cell activation syndrome. Int Arch Allergy Immunol. 2019;180(1):44-51.

39. Salas M, Gomez F, Fernandez TD, Dona I, Aranda A, Ariza A, et al. Diagnosis of immediate hypersensitivity reactions to radiocontrast media. Allergy. 2013;68(9):1203-6.

40. Pinnobphun P, Buranapraditkun S, Kampitak T, Hirankarn N, Klaewsongkram J. The diagnostic value of basophil activation test in patients with an immediate hypersensitivity reaction to radiocontrast media. Ann Allergy Asthma Immunol. 2011;106(5):387-93.

41. Trcka J, Schmidt C, Seitz CS, Brocker EB, Gross GE, Trautmann A. Anaphylaxis to iodinated contrast material: nonallergic hypersensitivity or IgE-mediated allergy? AJR Am J Roentgenol. 2008;190(3):666-70.

42. Lerch M, Keller M, Britschgi M, Kanny G, Tache V, Schmid DA, et al. Cross-reactivity patterns of T cells specific for iodinated contrast media. J Allergy Clin Immunol. 2007;119(6):1529-36.

43. Torres MJ, Gomez F, Dona I, Rosado A, Mayorga C, Garcia I, et al. Diagnostic evaluation of patients with nonimmediate cutaneous hypersensitivity reactions to iodinated contrast media. Allergy. 2012;67(7):929-3.

Study reporting the need for drug provocation test in $56 \%$ of 161 patients with nonimmediate reactions to $\mathrm{CM}$ and negative skin test.

44. Vernassiere C, Trechot P, Commun N, Schmutz JL, Barbaud A. Low negative predictive value of skin tests in investigating delayed reactions to radio-contrast media. Contact Dermatitis. 2004;50(6):359-66.

45. Vega F, Mugica MV, Argiz L, Bazire R, Belver MT, Friera A, et al. Protocol to prevent contrast-induced nephropathy in parenteral challenge tests for allergy evaluation of hypersensitivity reactions to iodinated contrast media. Clin Exp Allergy. 2021.

46. Park HJ, Park JW, Yang MS, Kim MY, Kim SH, Jang GC, et al. Re-exposure to low osmolar iodinated contrast media in patients with prior moderate-to-severe hypersensitivity reactions: A multicentre retrospective cohort study. Eur Radiol. 2017;27(7):2886-93.

47. Park SJ, Kang DY, Sohn KH, Yoon SH, Lee W, Choi YH, et al. Immediate mild reactions to CT with iodinated contrast media: strategy of contrast media readministration without corticosteroids. Radiology. 2018;288(3):710-6.

48. Amr BS, Lippmann M, Tobbia P, Isom N, Dalia T, Buechler T, et al. Impact of short term oral steroid use for intravenous contrast media hypersensitivity prophylaxis in diabetic patients undergoing nonemergent coronary angiography or interventions. Catheter Cardiovasc Interv. 2020;96(7):1392-8.

49. Carter MC, Metcalfe DD, Matito A, Escribano L, Butterfield JH, Schwartz LB, et al. Adverse reactions to drugs and biologics in patients with clonal mast cell disorders: a Work Group Report of the Mast Cells 
Disorder Committee, American Academy of Allergy, Asthma \& Immunology. J Allergy Clin Immunol. 2019;143(3):880-93.

50.• Park HJ, Son JH, Kim TB, Kang MK, Han K, Kim EH, et al. Relationship between lower dose and injection speed of iodinated contrast material for ct and acute hypersensitivity reactions: an observational study. Radiology. 2019;293(3):565-7.

Study reporting that the probability for a hypersensitivity depended on the dose and injection speed of RCM for CT in one cohort, which may have implications for the management of patients.

51. Zhang B, Liu J, Dong Y, Guo B, Lian Z, Yu H, et al. Extrinsic warming of low-osmolality iodinated contrast media to 37 degrees $C$ reduced the rate of allergiclike reaction. Allergy Asthma Proc. 2018;39(6):e55-6. In this study the probability for a hypersensitivity was reduced in three out of four low-osmolality RCM after extrinsic warming of the RCM to 37 degrees.

52. Gandhi S, Litt D, Chandy M, Nguyen BM, Jindal NL, Tarlo SM, et al. Successful rapid intravenous desensitization for radioiodine contrast allergy in a patient requiring urgent coronary angiography. J Allergy Clin Immunol Pract. 2014;2(1):101-2.
53. Brockow K. Include desensitization to radiocontrast media in the diagnostic algorithm. Allergy. 2021;76(4):1304-1305.

54. Schrijvers R, Breynaert C, Ahmedali Y, Bourrain JL, Demoly P, Chiriac AM. Skin testing for suspected iodinated contrast media hypersensitivity. J Allergy Clin Immunol Pract. 2018;6(4):1246-5.

Very large study on the value of skin testing in RCM hypersensitivity.

55. Dona I, Bogas G, Salas M, Testera A, Moreno E, Laguna JJ, et al. Hypersensitivity reactions to multiple iodinated contrast media. Front Pharmacol. 2020;11:575437.

56. Meucci E, Radice A, Fassio F, Sibilio M, Iorno MLC, Testi S, et al. Diagnostic approach to hypersensitivity reactions to iodinated contrast media: a single-center experience on 98 patients. Eur Ann Allergy Clin Immunol. 2020;52(5):220-9.

\section{Publisher's Note}

Springer Nature remains neutral with regard to jurisdictional claims in published maps and institutional affiliations. 